\title{
Vacinas no Brasil: análise histórica do registro sanitário e a disponibilização no Sistema de Saúde
}

\author{
Vaccines in Brazil: historical analysis of the Sanitary registration \\ and vaccine availability in the Brazilian Unified Health System
}

\author{
Kaite Cristiane Peres (https://orcid.org/0000-0001-6811-925X ) ${ }^{1}$ \\ Fabíola Bagatini Buendgens (https://orcid.org/0000-0002-0229-0852) ${ }^{2}$ \\ Ediana Adriano Prates (https://orcid.org/0000-0001-5632-1071) ${ }^{3}$ \\ Norberto Rech Bonetti (https://orcid.org/0000-0003-4808-4277) ${ }^{1}$ \\ Luciano Soares (https://orcid.org/0000-0001-7633-5681) ${ }^{4}$ \\ Claudia Marcela Vargas-Peláez (https://orcid.org/0000-0001-5011-8718) ${ }^{5}$ \\ Mareni Rocha Farias (https://orcid.org/0000-0002-4319-9318) ${ }^{1}$
}

${ }^{1}$ Centro de Ciências da Saúde, Universidade Federal de Santa Catarina. R. Delfino Conti S/N Trindade, 88040-370. Florianópolis SC Brasil.kaitecris@gmail.com ${ }^{2}$ Farmácia Escola, Universidade Federal de Santa Catarina. Florianópolis SC Brasil.

${ }^{3}$ Escola de Saúde Pública de Florianópolis. Florianópolis SC Brasil.

${ }^{4}$ Universidade da Região de Joinville. Joinville SC Brasil.

${ }^{5}$ Fundación IFARMA.

Bogotá Colômbia.

\begin{abstract}
Given the COVID-19 pandemic and the importance of public social protection policies, health issues, including immunizations, have gained prominence. This paper aims to analyze the dynamics of vaccine registration in Brazil and the vaccines made available through the National Immunization Program (PNI in Portuguese), with emphasis on the 2004-2018 vaccination schedule. This descriptive, exploratory, documentary research analyzed vaccine registration procedureswith the Brazilian Health Regulatory Agency (ANVISA, in Portuguese) and the incorporation of vaccine products into the PNI. The study drew on information from the national sanitary registration database, made available by ANVISA; a document analysis of official/normative publications; and data from published literature. The data shows the incorporation of vaccines into the PNI, evidencing that Brazil is a country with industrial potential for vaccine production but that is still focused on the transfer of technologies and in need of public attention and investments for developing new technologies as a way to ensure the sector's independence.
\end{abstract}

Key words Vaccines, Brazilian Health RegulatoryAgency, Biological products, Public Health
Resumo Com a pandemia da COVID-19 e a importância das políticas públicas de proteção social, questões sanitaristas incluindo as imunizações se tornaram destaque. O estudo tem o objetivo de analisar a dinâmica dos registros sanitários de vacinas no país e as vacinas disponibilizadas por meio do Programa Nacional de Imunização (PNI), com destaque para o calendário vacinal no período entre 2004 e 2018. Realizou-se um estudo descritivo, documental e exploratório dos processos de registro sanitário na Agência Nacional de Vigilância Sanitária (Anvisa) e a incorporação dos produtos no PNI. Como base da pesquisa foram utilizados o banco de dados de registro sanitário disponibilizado pela Anvisa, a análise documental de publicações oficiais/normativas e os dados da literatura. Os dados demonstram a incorporação das vacinas no PNI, assim como um país com potencial industrial para a produção das vacinas, no entanto ainda centrado na transferência de tecnologias, necessitando de investimentos e atenção pública no desenvolvimento de novas tecnologias, garantindo a independência do setor.

Palavras-chave Vacinas, Agência Nacional de Vigilância Sanitária, Produtos biológicos, Saúde Pública 


\section{Introdução}

A pandemia da COVID-19 tem ressaltado a importância das políticas públicas de proteção social, especialmente sanitárias e econômicas. As vacinas adquiriram protagonismo para o controle da pandemia e tornaram evidente o papel do Estado neste setor. As instituições de pesquisa, desenvolvimento e produção, tanto públicas, quanto privadas, bem como o papel da Agência Nacional de Vigilância Sanitária (Anvisa) e o Programa Nacional de Imunização (PNI) têm sido pautas frequentes na mídia. Neste contexto, analisar a dinâmica do registro de vacinas no Brasil e a incorporação destes produtos no PNI nos últimos 15 anos contribui para qualificar o debate e aprimorar as políticas públicas relacionadas.

O PNI, formulado em 1973, integra a missão de controlar e/ou erradicar doenças imunopreveníveis no território nacional ${ }^{1}$. Como Programa, deve articular as ações de imunização no país, que até então eram organizadas em campanhas de controle de doenças ${ }^{2,3}$. Seu escopo envolve estratégias para ampliar a rede de vacinação, alcançando a população rural, a vigilância epidemiológica, educação em saúde e a instituição de laboratórios nacionais equipados e capacitados a respaldar diagnósticos e realizar o controle da qualidade de vacinas ${ }^{4}$.

No contexto da criação do PNI, o suprimento de vacinas no Brasil era majoritariamente dependente de importações, o que resultava em baixa autonomia e grande vulnerabilidade na acessibilidade a estes insumos 5 . Em 1985, a instituição do Programa de Autossuficiência Nacional de Imunobiológicos, voltado ao atendimento das necessidades nacionais de vacinas e de soros, foi uma das estratégias para o desenvolvimento nacional do setor. Com o passar dos anos, os investimentos na estrutura e organização dos serviços de saúde, como por exemplo na rede de frio, possibilitaram as ações de vacinação universal'. Desde 2004, o país se destaca na erradicação e no controle de doenças imunopreveníveis como poliomielite, febre amarela urbana, e até mesmo o sarampo. No decorrer dos anos, além de distribuir as vacinas à população, via PNI, o Brasil também tornou-se exportador para mais de 70 países, especialmente no continente africano ${ }^{7}$.

No tocante ao atendimento dos marcos regulatórios-sanitários nacionais, compete aos laboratórios produtores a solicitação de registro sanitário e o provimento da documentação comprobatória dos dados clínicos, da capacidade de produção e da garantia da qualidade. Já aos órgãos reguladores, cabe a avaliação dos dados de segurança, eficácia e qualidade dos produtos, incluindo verificação in loco do cumprimento dos requisitos de Boas Práticas de Fabricação nas empresas $^{8}$, sendo que a adequada regulação do setor farmacêutico tende a elevar a confiança dos cidadãos no sistema de saúde e a contribuir para a comercialização destas tecnologias em condições mais adequadas ${ }^{9,10}$. No caso do Brasil esta função é cumprida pela Anvisa, agência regulatória criada em 1999, inspirada na Food and Drug Administration (FDA) dos Estados Unidos ${ }^{11,12}$.

Como parte do Sistema Único de Saúde (SUS), a vigilância sanitária configura-se como um espaço privilegiado de intervenção do Estado para elevar a qualidade de produtos e de serviços, e para adequar os segmentos produtivos de interesse da saúde e os ambientes às demandas sociais e às necessidades do sistema de saúde ${ }^{13}$. Como autoridade regulatória nacional, a Anvisa armazena o histórico dos produtos farmacêuticos registrados no país.

Sendo assim, este trabalho tem por objetivo analisar a dinâmica dos registros sanitários de vacinas no Brasil e as vacinas disponibilizadas por meio do PNI, com destaque para o calendário vacinal no período entre 2004 e 2018.

\section{Métodos}

Estudo descritivo, documental e exploratório referente aos registros sanitários de vacinas realizados no Brasil até 2018, e à disponibilização desses produtos no PNI, com destaque ao calendário vacinal no período entre 2004 e 2018. Considerou-se como marco inicial para as análises de incorporação dos produtos no PNI o primeiro calendário vacinal (2004) após a criação da Anvisa (1999).

Para obtenção dos dados, em 31 de dezembro de 2018, realizou-se uma consulta ao website da Anvisa ${ }^{14}$, em "Consultas de medicamentos e hemoderivados", incluindo o filtro "biológico" na categoria regulatória. Para a análise considerou-se apenas as vacinas destinadas a seres humanos. Os detalhes do registro sanitário (data de registro, empresa detentora e situação) foram consultados considerando o princípio ativo. Para complementar as informações sobre data de vencimento, motivo e data de cancelamento do registro sanitário (quando presente), realizou-se uma pesquisa ao website da Anvisa denominado "Situação de documentos - tipo de documento 
técnico" 15 , por meio do número do processo de registro sanitário das vacinas. Neste trabalho, considerou-se a situação dos processos de registro sanitário como ativo/vigente ou cancelado/ caduco, no momento da consulta (dezembro de 2018). Somente os produtos com registro sanitário como ativo/vigente podem ser comercializados no país. Cumpre salientar que a partir de 2019 houve uma mudança significativa no sistema de informação da Anvisa, tornando as ferramentas de busca mais ágeis.

Para comparar as vacinas registradas no país e a incorporação no PNI, realizou-se uma análise documental de publicações oficiais/normativas do Ministério da Saúde sobre os calendários vacinais existentes no período 2004 - 2018, bem como dados da literatura.

Os dados foram coletados e analisados no Microsoft Office Excel ${ }^{\circledR}$, versão 2016, e as variáveis apresentadas em valores absolutos.

O estudo foi elaborado com dados de acesso público, portanto não houve necessidade de avaliação e aprovação do Comitê de Ética em Pesquisa $^{16}$.

\section{Resultados}

\section{Registro sanitário de vacinas no Brasil}

Os registros sanitários de produtos comercializados antes de 1999, data de criação da Anvisa, encontram-se no website da agência a partir do recadastramento obrigatório de medicamentos executado pelas indústrias farmacêuticas, conforme Portaria no 801 , de 07 de outubro de $1998^{17}$.

Os primeiros registros sanitários de vacinas, datam em 1993 (vacinas contra hepatite B e a meningocócica BC). A partir dessa data, observa-se um perfil de crescimento anual do número de processos de vacinas registrados, com pico em 2010. Em dezembro de 2018, foram contabilizados 186 processos registrados no país na categoria vacinas, com 45,1\% $(n=84)$ em situação ativa (vigente) (Figura 1).

Observa-se que até o ano 2010 houve predomínio de novos registros de vacinas em relação àqueles cancelados/caducos, com as maiores frequências de novos registros em 1999, 2009 e 2010. Nos dois últimos anos, ocorreu um aumento nos processos de registro sanitário, principalmente da vacina influenza, representando $40,0 \%$ $(\mathrm{n}=35)$ do número total de vacinas registradas no período.
Entre os registros sanitários de vacinas retiradas do mercado no período de 1993-2018 $(\mathrm{n}=102$ registros sanitários), destaca-se: em $47,0 \%(n=48)$ destes, a empresa solicitou o cancelamento do registro, porém para esta situação, o motivo não é disponibilizado para consulta pública; em 26,5\% ( $\mathrm{n}=27)$, a empresa solicitou o cancelamento do registro sanitário devido à troca de titularidade, o que significa que a empresa transferiu a propriedade e, portanto, o direito de produção e comercialização do produto para outra empresa; em 20,6\% $(n=21)$ a empresa apresentou desinteresse em renovar o registro sanitário após os cinco anos de comercialização (considerando a legislação vigente no período do estudo); em 5,0\% $(n=5)$ o registro foi cancelado pela Anvisa, normalmente por ação de farmacovigilância; e em $0,9 \%(n=1)$ não havia informações a respeito.

Entre os medicamentos com registro sanitário cancelado/caduco destacam-se os picos apresentados em 2011, 2012, 2016 e 2017. A troca de titularidade foi o principal motivo de cancelamento nos anos de 2011, 2012 e 2017. O número de cancelamentos por troca de titularidade nestes três anos representa $48,2 \%(n=13)$ dos 27 produtos cancelados por este motivo durante os 15 anos de estudo. Já em 2016, predominou o cancelamento dos processos da vacina influenza.

A Tabela 1 mostra que quatro empresas públicas e 21 empresas privadas foram detentoras de registro de vacina em algum momento do período estudado. Entre as empresas privadas observase que algumas passaram por processo de fusão e outras não mantiveram o registro das vacinas, corroborando os dados de cancelamento por troca de titularidade (nos casos de fusão de empresas) e de não renovação do registro. Em dezembro de 2018, apenas oito empresas privadas possuíam registros ativos. As empresas privadas detêm $80,6 \%$ dos registros no período e desses $69,0 \%$ dos registros ativos, com concentração em três empresas: Sanofi-Aventis (25,0\% dos registros ativos), GlaxoSmithKline Brasil (22,6\%) e Merck Sharp \& Dohme $(11,9 \%)$, as outras cinco empresas privadas possuem 9,5\% dos registros ativos. As quatro empresas públicas, Fundações Ataulpho de Paiva, Ezequiel Dias - Funed, Oswaldo Cruz e o Instituto Butantan computaram 19,4\% dos processos de registro de vacinas cadastrados no período de 2004 a 2018 e, em dezembro de 2018 detinham $31,0 \%$ dos registros ativos. 


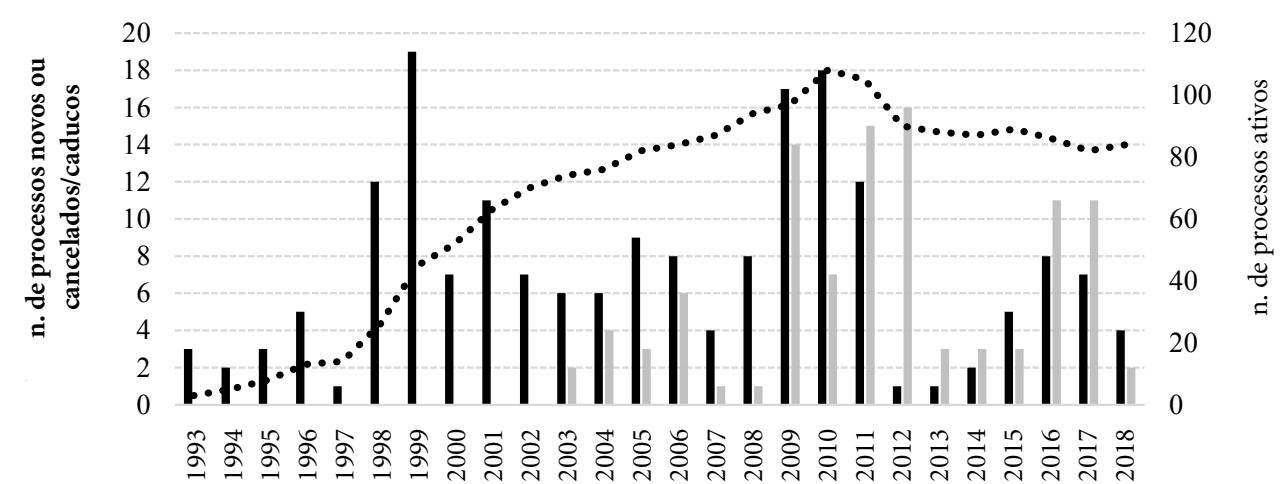

Ano

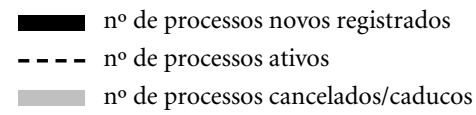

Figura 1. Número (n) de processos com registro sanitário ativo (vigente), cancelado/caduco e os novos registros sanitários, anualmente, na Agência Nacional de Vigilância Sanitária (Anvisa) consultados em 31 de dezembro de 2018.

Fonte: Elaboração própria a partir dos dados coletados da Agência Nacional de Vigilância Sanitária - Anvisa.

\section{Programa Nacional de Imunização e o Calendário Vacinal}

O PNI integra as vacinas que compõem o calendário vacinal, sendo que até 2013 as novas portarias revogavam as anteriores, criando novos calendários. Com a Portaria Ministerial no $1.498 / 2013^{18}$, o calendário vacinal é estabelecido com as atualizações, caso ocorram, por meio de informes/Notas Técnicas anuais, que publicam a ampliação da população a ser atendida por algum produto, ou então a disponibilização de novos produtos de forma complementar ao calendário vacinal, a depender das necessidades do país, como a vacina da raiva ou de COVID-19. Nestes casos, situações de emergência ou excepcionalidade determinam as vacinas disponibilizadas ou a alteração da população alvo.

As atualizações dos calendários vacinais por meio de informes e notas técnicas são de responsabilidade da coordenação geral do PNI. Ampliação de faixas etárias ou inclusão de novas vacinas (como ocorreu de 2013-2020 a inclusão de HPV, Hepatite A, tetra viral e COVID-19) são as alterações mais frequentes, conforme os dados apresentados na Figura 2.

Um aspecto concernente à Figura 2 refere-se à população alvo, que dimensiona a cobertura oferecida por grupos etários ou categorias, porém não especifica exatamente a idade que abrange. Por exemplo, a vacina HPV era fornecida em 2014 apenas para meninas de 11 a 13 anos, no ano seguinte ampliou a cobertura para crianças de 9-13 anos, e em 2017 meninas de 9-14 anos e, meninos e meninas de 9-26 anos vivendo com HIV/ Aids, transplantados de órgãos sólidos, de medula óssea e pacientes oncológicos; para a população indígena a vacinação ocorre desde 2014 de 9-13 anos. Observa-se cobertura mais abrangente para algumas vacinas, como febre amarela, e outras dirigidas a populações específicas, como varicela e dTpa. As vacinas presentes em campanhas de vacinação, consideram a necessidade do período para definir a população a ser contemplada. Assim, no decorrer dos anos a ampliação do acesso considera o perfil epidemiológico e o risco sanitário como princípios de incorporação de vacinas ao PNI.

\section{Registro Sanitário das vacinas e PNI 2004-2018}

$\mathrm{Na}$ Tabela 2 estão apresentados os registros sanitários das vacinas e, se incorporadas no PNI a partir de 2004, a data de incorporação. Apresentou-se também o número de registros ativos, cancelados/caducos e as empresas detentoras dos 
Tabela 1. Número de processos de vacinas registrados na Agência Nacional de Vigilância Sanitária - Anvisa até 31/12/2018; e situação dos processos em 31 de dezembro de 2018, por empresa detentora de registro.

\begin{tabular}{|c|c|c|}
\hline Empresa detentora do registro sanitário & $\begin{array}{c}\text { Número total de } \\
\text { processos no período }\end{array}$ & $\begin{array}{c}\text { Número de processos } \\
\text { ativos em dezembro } \\
2018\end{array}$ \\
\hline \multicolumn{3}{|l|}{ Empresas privadas } \\
\hline Abbott Laboratórios do Brasil LTDA & 2 & 2 \\
\hline Abbott Produtos para Saúde LTDA & 1 & 0 \\
\hline Astrazeneca do Brasil LTDA & 1 & 0 \\
\hline Baxter Hospitalar LTDA & 3 & 0 \\
\hline Biotest Farmacêutica LTDA & 1 & 0 \\
\hline Blau Farmacêutica S.A. & 3 & 0 \\
\hline Brasvit Indústria e Comércio LTDA & 2 & 0 \\
\hline Cristália Produtos Químicos Farmacêuticos LTDA & 4 & 0 \\
\hline Cubanacan Comércio Internacional LTDA & 2 & 0 \\
\hline GlaxoSmithKline Brasil LTDA & 31 & 19 \\
\hline Laboratórios Pfizer LTDA & 2 & 2 \\
\hline Medstar Importação e Exportação Eireli & 2 & 2 \\
\hline Merck Sharp \& Dohme Farmacêutica LTDA & 11 & 10 \\
\hline Novartis Biociências S.A & 12 & 1 \\
\hline Novo Nordisk Produção Farmacêutica do Brasil LTDA & 1 & 0 \\
\hline Nutoth - Pharma Indústria e Comércio LTDA & 2 & 0 \\
\hline Prophylaxis Clinica de Vacinação LTDA & 2 & 0 \\
\hline Sanofi Pasteur LTDA & 30 & 0 \\
\hline Sanofi-Aventis Farmacêutica LTDA & 34 & 21 \\
\hline UCB Biopharma LTDA & 1 & 1 \\
\hline Wyeth Indústria Farmacêutica LTDA & 3 & 0 \\
\hline \multicolumn{3}{|l|}{ Empresas públicas } \\
\hline Fundação Ataulpho de Paiva & 2 & 2 \\
\hline Fundação Ezequiel Dias - Funed & 1 & 1 \\
\hline Fundação Oswaldo Cruz & 15 & 11 \\
\hline Instituto Butantan & 18 & 12 \\
\hline Totais & 186 & 83 \\
\hline
\end{tabular}

Fonte: Elaboração própria a partir dos dados coletados da Agência Nacional de Vigilância Sanitária - Anvisa.

registros, inclusive os registros ativos em dezembro de 2018; assim como o ano do primeiro registro de laboratório público e de empresa privada, para cada vacina.

Os dados da Tabela 2 somam 181 registros de 45 vacinas diferentes no período de 2004 a 2018. Considerando o total de registros na Anvisa (186) foram identificados cinco registros de vacina isolada contra o sarampo, disponibilizada a partir de 1977, porém no calendário vacinal, a partir de 2004 a imunização contra sarampo está incorporada na vacina tríplice viral.

Em relação às vacinas incorporadas no PNI a partir de 2004, foram identificados 142 registros de 25 vacinas diferentes até 2018. Com exceção das vacinas BCG e febre amarela, o primeiro re- gistro sanitário é de empresa privada e posteriormente na empresa pública. Entre os registros de vacinas do PNI, $107(75,4 \%)$ são de empresas privadas e 35 (24,6\%) de empresas públicas. Em dezembro de 2018, 67 (47,2\%) registros estavam ativos e destes $41(61,2 \%)$ pertencem a empresas privadas e $38,8 \%(n=26)$ a empresas públicas. $\mathrm{O}$ cancelamento de registros de vacinas do PNI entre as empresas privadas representou $61,7 \%$ $(n=66)$ dos registros deste setor, enquanto que entre as empresas públicas os cancelamentos representaram 25,7\% ( $n=9)$ dos registros do setor (Tabela 1).

Em relação às vacinas não incorporadas no PNI (20 vacinas diferentes), foram localizados 39 registros sanitários no período de 2004 a 2018, 


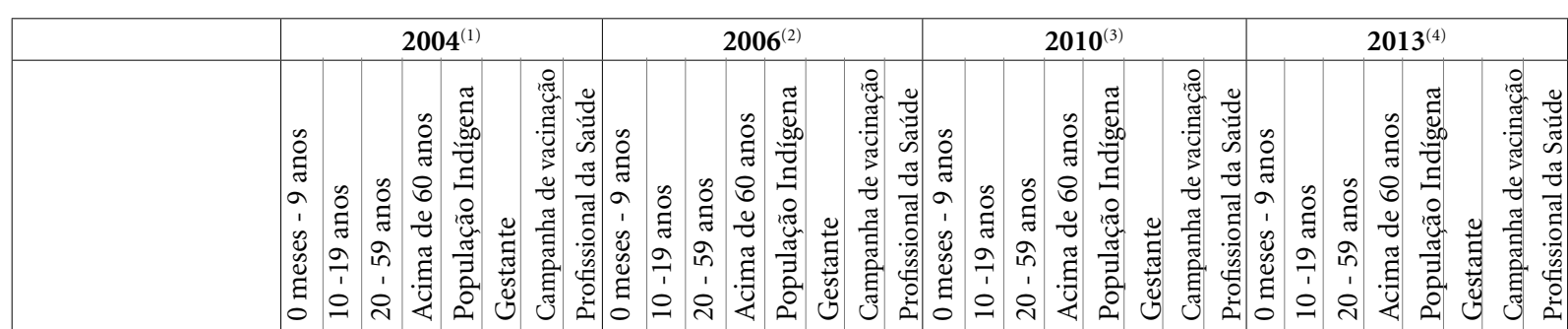

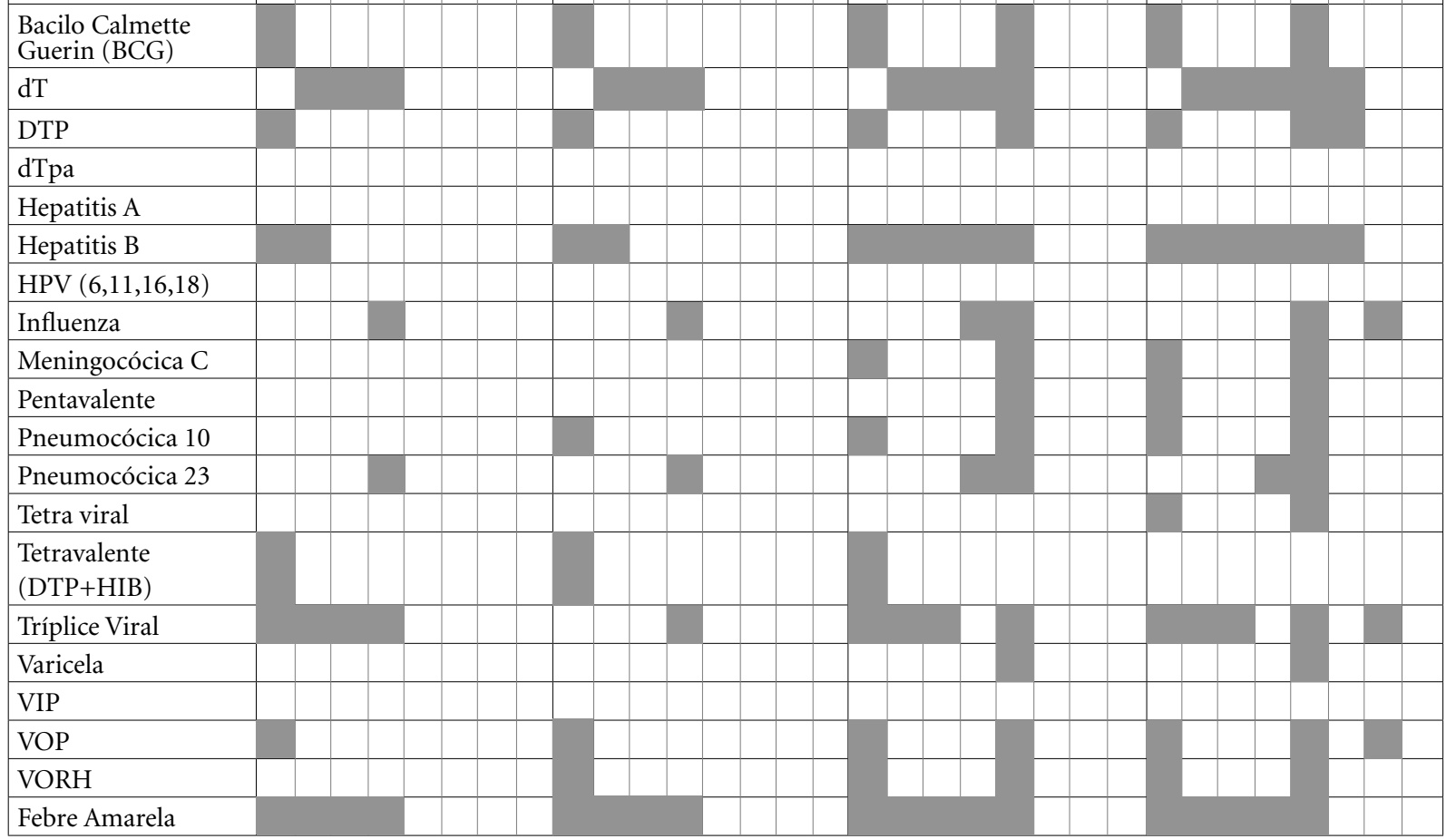

continua

Figura 2. Vacinas disponíveis por categoria/faixa etária e normativas abrangentes dos calendários vacinais presentes no Programa Nacional de Imunização (PNI), no período de 2004-2018 no Brasil.

todos de empresas privadas, e destes, $17(43,6 \%)$ estavam ativos em dezembro de 2018, correspondendo a 11 vacinas que, em parte, variam no tipo de associação. Os cancelamentos de registro entre as vacinas não incorporadas representaram $56,4 \%$ (22), muitas vezes pela incorporação da vacina isolada em uma associação ou ampliação das linhagens dos agentes infecciosos.

Entre as 25 vacinas presentes no PNI, no período em análise, observa-se que duas não possuem produtos com registro ativo no país (Penta e Dupla viral). As vacinas Pneumococo 23, Varicela e Febre tifoide apresentam registros apenas de laboratórios privados, sendo que a vacina $\mathrm{dT}$
(Dupla adulto contra Difteria e Tétano) apenas em laboratório público. A maioria possui produtos com registro ativo tanto em laboratórios públicos quanto privados (Tabela 2).

Em relação às empresas produtoras, com exceção da Pfizer, as outras sete empresas que permaneceram com registros ativos em dezembro de 2018, são vacinas que constam no PNI. Abbott, Medstar, Novartis e UBC possuem somente o registro da vacina influenza ativo. Sanofi-Aventis, GlaxoSmithKline e Merck Sharp \& Dohme possuem registro ativo de vacinas que, individualmente integram o PNI, bem como de associações que são disponibilizadas no mercado privado. 


\begin{tabular}{|l|l|l|l|l|l|l|l|l|l}
\hline & \\
\hline
\end{tabular}

Legenda:

Vacinas incorporadas no Programa Nacional de Imunização (PNI)

BCG = Bacilo Calmette Guerin; $\mathrm{dT}=$ Vacina Dupla adulto contra Difteria e Tétano;

DTP = Vacina tríplice bacteriana - contra difteria, tétano e coqueluche;

dTpa = Vacina adsorvida difteria, tétano e coqueluche (Pertussis Acelular) tipo adulto; HIB = Haemophilus influenzae B; HPV = Papiloma vírus humano; Tríplice Viral $=$ vacina contra sarampo, rubéola e caxumba; Tetra viral = Vacina contra sarampo, caxumba, rubéola e varicela atenuada;

VIP $=$ Vacina inativida Poliomielite;

VORH $=$ Vacina Oral Rotavírus Humano;

VOP = Vacina Oral Poliomielite; Pentavalente $=$ Tetravalente $($ DTP + HIB) + hepatite B.

(1) Portaria no 597: Instituição dos Calendários Básicos de Vacinação da Criança, do Adolescente e do Adulto e Idoso; (2) Portaria no 1.602: Atualização dos Calendários de Vacinação da Criança, do Adolescente, do Adulto e do Idoso; (3) Portaria no 1.946: Instituição, em todo o território nacional, do Calendário de Vacinação para os Povos Indígenas e Portaria no 3318: Atualização dos Calendários de Vacinação da Criança, do Adolescente, do Adulto e do Idoso; (4) Portaria no 1.498: Atualização e redefinição do Calendário Nacional de Vacinação, do Calendário Nacional de Vacinação dos Povos Indígenas e das Campanhas Nacionais de Vacinação; e Informe técnico de introdução da vacina tetra viral (sarampo, caxumba, rubéola e varicela atenuada); (5) Informe técnico de introdução da vacina HPV; Informe técnico de introdução da vacina hepatite A e Informe técnico para Implantação da Vacina Adsorvida Difteria, Tétano e Coqueluche (Pertussis Acelular) Tipo adulto - dTpa; (6) Nota Informativa 149: Mudanças no Calendário Nacional de Vacinação para 2016; (7) Nota Informativa 384: Mudanças no Calendário Nacional de Vacinação para 2017; Nota Informativa 94: Orientação e Indicação de dose única da vacina Febre Amarela; Nota Informativa 154- Ampliação da Faixa Etária da vacina Papiloma vírus humano; Informe técnico da ampliação da oferta das vacinas papilomavírus humano 6,11, 16 e 18 (recombinante) - vacina HPV quadrivalente e meningocócica C (conjugada).

* Nota: mesmo com a publicação da Nota Informativa no 135-SEi/2017-CGPNI/DEVIT/SVS/MS, referente ao calendário 2018, segundo a disponibilização das faixas etárias apresentadas na Figura 2, a apresentação se torna igual 2017, por isto não apresentada na figura.

Figura 2. Vacinas disponíveis por categoria/faixa etária e normativas abrangentes dos calendários vacinais presentes no Programa Nacional de Imunização (PNI), no período de 2004-2018 no Brasil.

Fonte: Elaboração própria a partir de publicações oficiais/normativas do Ministério da Saúde sobre os calendários vacinais existentes no período 2004 2018.

\section{Discussão}

Apesar da adoção de programas de vacinação ocorrer desde 1925 e do Brasil contar com um calendário vacinal desde 1977, os primeiros re- gistros sanitários desta categoria no banco de dados da Anvisa remontam 1993. A construção do banco de dados de registro de produtos ocorreu a partir do recadastramento realizado conforme a Portaria no 801 , de 07 de outubro de $1998^{17}$. Por- 
tanto, a informação sobre registros anteriores a 1998, que não foram renovados, por falta de interesse da empresa ou por já terem cancelado o re- gistro não ficou cadastrada e estas não integram o banco de dados.

Tabela 2. Representação do número de processos (ativos ou cancelados/caducos) de vacinas na Agência Nacional de Vigilância Sanitária (Anvisa) em 31/12/2018, considerando as vacinas incorporadas ou não incorporadas no Programa Nacional de Imunizações (PNI) a partir de 2004. As variáveis independentes são: empresa detentora do registro e o tipo (pública ou privada), o ano de incorporação da vacina no calendário vacinal, no período de 2004 -2018.

\begin{tabular}{|c|c|c|c|c|c|c|}
\hline & $\begin{array}{l}\text { Primeiro } \\
\text { registro- } \\
\text { empresa } \\
\text { privada }\end{array}$ & $\begin{array}{l}\text { Primeiro } \\
\text { registro- } \\
\text { empresa } \\
\text { pública }\end{array}$ & $\begin{array}{c}\text { Ano de } \\
\text { incorporação } \\
\text { no PNI }\end{array}$ & $\begin{array}{c}\text { Número } \\
\text { total de } \\
\text { processos } \\
\text { cancelados/ } \\
\text { caducos } \\
\text { (empresa } \\
\text { pública) }\end{array}$ & $\begin{array}{l}\text { Número } \\
\text { total de } \\
\text { processos } \\
\text { ativos } \\
\text { (empresa } \\
\text { pública) }\end{array}$ & $\begin{array}{l}\text { Empresas detentoras do } \\
\text { registro sanitário } \\
\text { (número de registro ativo } \\
\text { em dez 2018) }\end{array}$ \\
\hline $\begin{array}{l}\text { Bacilo Calmette Guerin } \\
\text { (BCG) }\end{array}$ & - & 1998 & $2004^{*}$ & $1(1)$ & $2(2)$ & $\mathrm{J}(2) ; \mathrm{N}(0)$ \\
\hline Cólera & 2004 & - & NI & $2(0)$ & $0(0)$ & $\mathrm{V}(0) ; \mathrm{X}(0)$ \\
\hline DT & 1996 & 2003 & 2004 & $2(0)$ & $2(2)$ & $\mathrm{N}(2) ; \mathrm{R}(0) ; \mathrm{V}(0)$ \\
\hline DTP & 1995 & 2003 & $2004^{*}$ & $1(0)$ & $3(1)$ & $\mathrm{M}(1) ; \mathrm{N}(1) ; \mathrm{V}(0) ; \mathrm{X}(1)$ \\
\hline DTP + Hepatite B & 2000 & - & NI & $1(0)$ & $0(0)$ & $\mathrm{M}(0)$ \\
\hline $\mathrm{DTP}+\mathrm{VIP}$ & 1994 & - & $\mathrm{NI}$ & $3(0)$ & $3(0)$ & $\mathrm{M}(1) ; \mathrm{V}(0) ; \mathrm{X}(2)$ \\
\hline $\mathrm{DTP}+\mathrm{VIP}+\mathrm{HIB}$ & 1999 & - & $\mathrm{NI}$ & $3(0)$ & $2(0)$ & $\mathrm{M}(1) ; \mathrm{V}(0) ; \mathrm{X}(1)$ \\
\hline $\begin{array}{l}\mathrm{DTP}+\mathrm{VIP}+\mathrm{HIB}+ \\
\text { Hepatite B }\end{array}$ & 2001 & - & NI & $0(0)$ & $3(0)$ & $\mathrm{M}(2) ; \mathrm{X}(1)$ \\
\hline $\begin{array}{l}\mathrm{DTP}+\mathrm{VIP}+\mathrm{HIB}+ \\
\text { Tétano }\end{array}$ & & - & NI & $2(0)$ & $0(0)$ & $\mathrm{V}(0)$ \\
\hline DTPa & 1998 & 2016 & 2014 & $1(0)$ & $3(1)$ & $\mathrm{M}(1) ; \mathrm{N}(1) ; \mathrm{V}(0) ; \mathrm{X}(1)$ \\
\hline Dupla Viral ${ }^{\star * *}$ & 2000 & - & - & $3(0)$ & $0(0)$ & $\mathrm{M}(0) ; \mathrm{V}(0) ; \mathrm{X}(0)$ \\
\hline Febre Amarela & 2006 & 1999 & 2004 & $1(0)$ & $2(1)$ & $\mathrm{L}(1) ; \mathrm{V}(0) ; \mathrm{X}(1)$ \\
\hline Febre Amarela + dengue & 2015 & - & NI & $0(0)$ & $1(0)$ & $\mathrm{X}(1)$ \\
\hline Hepatite A & 1996 & 2016 & 2014 & $3(0)$ & $4(1)$ & $\begin{array}{c}\mathrm{H}(0) ; \mathrm{M}(1) ; \mathrm{N}(1) ; \mathrm{Q}(1) ; \\
\mathrm{V}(0) ; \mathrm{X}(1)\end{array}$ \\
\hline Hepatite A e B & 1998 & - & NI & $0(0)$ & $1(0)$ & $\mathrm{M}(1)$ \\
\hline Hepatite B & 1993 & 1999 & 2004 & $2(0)$ & $5(2)$ & $\begin{array}{c}\mathrm{I}(0) ; \mathrm{M}(1) ; \mathrm{N}(2) ; \mathrm{Q}(1) ; \mathrm{V}(0) ; \\
\mathrm{X}(1)\end{array}$ \\
\hline HIB + Tétano & 1998 & - & NI & $1(0)$ & $1(0)$ & $\mathrm{M}(0) ; \mathrm{X}(1)$ \\
\hline $\operatorname{HPV}(16,18)$ & 2008 & - & NI & $0(0)$ & $1(0)$ & $\mathrm{M}(1)$ \\
\hline $\operatorname{HPV}(6,11,16,18)$ & 2006 & 2015 & 2014 & $0(0)$ & $2(1)$ & $\mathrm{N}(1) ; \mathrm{Q}(1)$ \\
\hline $\begin{array}{l}\text { HPV } \\
(6,18,16,11,58,52,45,33,31)\end{array}$ & 2017 & - & NI & $0(0)$ & $1(0)$ & $\mathrm{Q}(1)$ \\
\hline Influenza & 1997 & 2000 & 2004 & $26(4)$ & $13(2)$ & $\begin{array}{c}\mathrm{A}(2) ; \mathrm{B}(0) ; \mathrm{C}(0) ; \mathrm{D}(0) ; \mathrm{F}(0) ; \\
\mathrm{H}(0) ; \mathrm{L}(1) ; \mathrm{M}(1) ; \mathrm{N}(1) ; \\
\mathrm{P}(2) ; \mathrm{Q}(0) ; \mathrm{R}(1) ; \mathrm{T}(0) ; \mathrm{U}(0) ; \\
\mathrm{V}(0) ; \mathrm{X}(4) ; \mathrm{Y}(1)\end{array}$ \\
\hline Leishmaniose & 2001 & - & NI & $1(0)$ & $0(0)$ & $S(0)$ \\
\hline Meningite C + HIB & 2007 & - & NI & $1(0)$ & $0(0)$ & $\mathrm{M}(0)$ \\
\hline $\begin{array}{l}\text { Meningocócica } \\
\text { A,C,Y,W-135 }\end{array}$ & 2014 & - & NI & $1(0)$ & $2(0)$ & $\mathrm{M}(1) ; \mathrm{O}(1)$ \\
\hline Meningocócica AC ${ }^{\star * *}$ & 1995 & 2005 & - & $3(0)$ & $2(1)$ & $\mathrm{L}(1) ; \mathrm{R}(0) ; \mathrm{V}(0) ; \mathrm{X}(1)$ \\
\hline
\end{tabular}


Tabela 2. Representação do número de processos (ativos ou cancelados/caducos) de vacinas na Agência Nacional de Vigilância Sanitária (Anvisa) em 31/12/2018, considerando as vacinas incorporadas ou não incorporadas no Programa Nacional de Imunizações (PNI) a partir de 2004. As variáveis independentes são: empresa detentora do registro e o tipo (pública ou privada), o ano de incorporação da vacina no calendário vacinal, no período de 2004 -2018.

\begin{tabular}{|c|c|c|c|c|c|c|}
\hline & $\begin{array}{l}\text { Primeiro } \\
\text { registro- } \\
\text { empresa } \\
\text { privada }\end{array}$ & $\begin{array}{l}\text { Primeiro } \\
\text { registro- } \\
\text { empresa } \\
\text { pública }\end{array}$ & $\begin{array}{c}\text { Ano de } \\
\text { incorporação } \\
\text { no PNI }\end{array}$ & $\begin{array}{l}\text { Número } \\
\text { total de } \\
\text { processos } \\
\text { cancelados/ } \\
\text { caducos } \\
\text { (empresa } \\
\text { pública) }\end{array}$ & $\begin{array}{l}\text { Número } \\
\text { total de } \\
\text { processos } \\
\text { ativos } \\
\text { (empresa } \\
\text { pública) }\end{array}$ & $\begin{array}{l}\text { Empresas detentoras do } \\
\text { registro sanitário } \\
\text { (número de registro ativo } \\
\text { em dez 2018) }\end{array}$ \\
\hline Meningocócica BC & 1993 & - & $\mathrm{NI}$ & $1(0)$ & $0(0)$ & $\mathrm{I}(0)$ \\
\hline Meningocócica B & 2015 & - & NI & $1(0)$ & $1(0)$ & $\mathrm{M}(1) ; \mathrm{R}(0)$ \\
\hline Meningocócica C & 2001 & 2009 & 2010 & $3(0)$ & $2(1)$ & $\mathrm{F}(0) ; \mathrm{K}(1) ; \mathrm{M}(1) ; \mathrm{R}(0) ; \mathrm{Z}(0)$ \\
\hline Meningocócica C + Tétano & 2002 & - & NI & $1(0)$ & $0(0)$ & $\mathrm{D}(0)$ \\
\hline Pentavalente & 2007 & - & 2010 & $1(0)$ & $0(0)$ & $\mathrm{M}(0)$ \\
\hline Pneumocócica 10 & 2009 & 2012 & 2010 & $0(0)$ & $2(1)$ & $\mathrm{L}(1) ; \mathrm{M}(1)$ \\
\hline Pneumocócica 13 & 2010 & - & NI & $1(0)$ & $1(0)$ & $\mathrm{O}(1) ; \mathrm{Z}(0)$ \\
\hline Pneumocócica 23 & 1995 & - & 2004 & $2(0)$ & $1(0)$ & $\mathrm{Q}(1) ; \mathrm{V}(0) ; \mathrm{X}(0)$ \\
\hline Pneumocócica 7 & 2001 & - & NI & $1(0)$ & $0(0)$ & $\mathrm{Z}(0)$ \\
\hline Raiva $^{* *}$ & 1998 & 2004 & - & $5(2)$ & $3(2)$ & $\mathrm{N}(2) ; \mathrm{R}(0) ; \mathrm{T}(0) ; \mathrm{V}(0) ; \mathrm{X}(1)$ \\
\hline Rubéola & 1994 & - & NI & $2(0)$ & $0(0)$ & $\mathrm{G}(0) ; \mathrm{V}(0)$ \\
\hline Tétano ${ }^{* *}$ & 1996 & 2003 & - & $1(0)$ & $2(1)$ & $\mathrm{N}(1) ; \mathrm{V}(0) ; \mathrm{X}(1)$ \\
\hline Tetra viral & 2008 & 2015 & 2013 & $0(0)$ & $3(1)$ & $\mathrm{L}(1) ; \mathrm{M}(1) ; \mathrm{Q}(1) ;$ \\
\hline Tetravalente (DTP + HIB) & 1996 & 2002 & 2004 & $2(1)$ & $2(1)$ & $\mathrm{L}(1) ; \mathrm{V}(0) ; \mathrm{X}(1)$ \\
\hline Tifóide ${ }^{\star * *}$ & 2006 & - & - & $1(0)$ & $1(0)$ & $\mathrm{V}(0) ; \mathrm{X}(1)$ \\
\hline Tríplice Viral & 1996 & 2004 & 2004 & $4(0)$ & $3(1)$ & $\begin{array}{l}\mathrm{L}(1) ; \mathrm{M}(1) ; \mathrm{Q}(1) ; \mathrm{R}(0) ; \\
\mathrm{U}(0) ; \mathrm{V}(0) ; \mathrm{X}(0)\end{array}$ \\
\hline Varicela & 1998 & - & 2010 & $4(0)$ & $3(0)$ & $\begin{array}{c}\mathrm{E}(0) ; \mathrm{G}(0) ; \mathrm{M}(1) ; \mathrm{Q}(2) ; \mathrm{V}(0) ; \\
\mathrm{X}(0)\end{array}$ \\
\hline VIP & 1998 & 1999 & 2013 & $4(1)$ & $2(1)$ & $\mathrm{F}(0) ; \mathrm{L}(1) ; \mathrm{M}(0) ; \mathrm{V}(0) ; \mathrm{X}(1)$ \\
\hline VOP & 1998 & 2007 & $2004^{*}$ & $5(0)$ & $2(2)$ & $\mathrm{L}(2) ; \mathrm{M}(0) ; \mathrm{R}(0) ; \mathrm{V}(0) ; \mathrm{X}(0)$ \\
\hline VORH & 2005 & 2010 & 2006 & $0(0)$ & $3(1)$ & $\mathrm{L}(1) ; \mathrm{M}(1) ; \mathrm{Q}(1)$ \\
\hline Totais & & & & 97 (9) & $84(26)$ & \\
\hline
\end{tabular}

Fonte: Elaboração própria a partir dos dados coletados da Agência Nacional de Vigilância Sanitária - Anvisa.

Legenda: dez= dezembro; NI= não incorporada no Programa Nacional de Imunização (PNI); DTP= tríplice bacteriana (contra difteria, tétano e coqueluche); HIB= Haemophilus Influenzae B; HPV= Papiloma vírus humano; VIP= vacina inativa poliomielite; dT= dupla adulto (difteria e tétano); $\mathrm{dTpa}=$ vacina adsorvida difteria, tétano e coqueluche (Pertussis Acelular); VORH= vacina oral rotavírus humano; Tríplice Viral= sarampo, caxumba e rubéola; Tetra viral= sarampo, caxumba, rubéola e varicela atenuada; $\mathrm{VOP}=$ vacina oral poliomielite adulto; $\mathrm{A}=\mathrm{Abbott}$ Laboratórios do Brasil LTDA; $B=$ Abbott Produtos para Saúde LTDA; $C=$ Astrazeneca do Brasil LTDA; $D=$ Baxter Hospitalar LTDA; E= Biotest Farmacêutica LTDA; F= Blau Farmacêutica S.A.; G= Brasvit Indústria e Comércio LTDA; H= Cristália Produtos Químicos Farmacêuticos LTDA; I= Cubanacan Comércio Internacional LTDA; J= Fundação Ataulpho de Paiva; K= Fundação Ezequiel Dias; L= Fundação Oswaldo Cruz; M= GlaxoSmithKline Brasil LTDA; $\mathrm{N}=$ Instituto Butantan; $\mathrm{O}=$ Laboratórios Pfizer LTDA; P= Medstar Importação e Exportação Eireli; Q= Merck Sharp \& Dohme Farmacêutica LTDA; $\mathrm{R}=$ Novartis Biociências S.A; $\mathrm{S}=$ Novo Nordisk Produção Farmacêutica do Brasil LTDA; T= Nutoth - Pharma Indústria e Comércio LTDA; U= Prophylaxis Clinica de Vacinação LTDA; V= Sanofi Pasteur LTDA; X= Sanofi-Aventis Farmacêutica LTDA; Y= UCB Biopharma LTDA; Z= Wyeth Indústria Farmacêutica LTDA.

Nota: *Vacinas presentes no calendário vacinal em 2004, entretanto já eram incorporadas desde o primeiro calendário vacinal básico, $1977 ;$ ** vacinas incorporadas no PNI, mas disponibilizadas para caso ocorra necessidade; ${ }^{\star \star \star}$ vacinas produzidas excepcionalmente, em caso de surtos ou para exportação, integrantes do PNI. 
Historicamente, para entender o sucesso do setor de vacinas é preciso considerar desde o século XIX, em que diversos laboratórios marcaram o desenvolvimento no setor como: o Instituto de Tecnologia em Imunobiológicos/Bio-Manguinhos que produziu a vacina contra a febre amarela, utilizando a cepa 17DD; o Instituto Butantan que consolidou a produção da vacina tríplice bacteriana (DTP); a Fundação Ataulpho de Paiva que passou a produzir as vacinas contra tuberculose; e o Instituto do Paraná (Tecpar) que desenvolveu a produção de vacina contra raiva ${ }^{5,8,19}$.

A partir dos registros presentes no banco de dados da Anvisa, observa-se um aumento significativo do registro de novos produtos nos anos 1998 e 1999, principalmente por empresas privadas, provavelmente, pela institucionalização da Anvisa, que possibilitou uma reorganização sanitária no país. Entre 2000 e 2008, o cenário de novos registros e cancelamentos de registros mostra-se bastante dinâmico, com uma curva crescente no número de processos ativos. Neste período observa-se importante desenvolvimento biotecnológico, promovendo novas perspectivas de produção de vacinas e o interesse das grandes empresas neste mercado, inclusive pela ampliação do $\mathrm{PNI}^{8}$.

Entre os anos de 2009 e 2010, ocorreu um aumento significativo de novos registros sanitários, fator correlacionado à pandemia do vírus influenza que atingiu o Brasil em maio de 2009. Entre as estratégias de controlar a situação, em 2009 foi firmada uma parceria entre o Instituto Butantan e a Sanofi Pasteur para efetuar a transferência de tecnologia. Esta estratégia possibilita, do ponto de vista de quem transfere, a ampliação do mercado local e a expansão na produção. Da perspectiva da regulação nacional, esta estratégia envolveu uma via regulatória diferenciada para produtos com prioridade para registros, além de exclusividade temporária do mercado público por meio das compras de medicamentos adotadas pelo sistema de saúde. Em contrapartida, os laboratórios que recebem a tecnologia abreviam o caminho para desenvolver um produto e garantir o acesso à tecnologia, com maior garantia de sustentabilidade financeira ${ }^{20}$.

A parceria em 2009 para a produção das vacinas influenza possibilitou o fornecimento das vacinas para a população brasileira, e permitiu que o Instituto Butantan se preparasse para ampliar sua produção ${ }^{21}$. Em 2018, o Instituto Butantan ampliou suas instalações e em 2020, tornou-se o maior produtor de vacinas contra influenza do Hemisfério Sul, exportando para países asiáticos ${ }^{22,23}$.
Os dados mostram que o PNI pode ser considerado como um impulsionador da produção nacional, por meio da negociação da transferência de tecnologia, que amplia a possibilidade de desenvolvimento e produção de vacinas no país. Esse processo ocorreu também com outras vacinas integrantes do calendário vacinal, como o contrato entre Glaxosmithkline e Bio-Manguinhos/Fundação Oswaldo Cruz, para transferência de tecnologia para produção das vacinas tríplice viral, tetravalente, pneumococo 10 , e rotavírus $^{20}$. Cabe ressaltar que também existe uma parceria de transferência de tecnologia com a empresa Sanofi Pasteur e Bio-Manguinhos/Fundação Oswaldo Cruz para a vacina inativada poliomielite ${ }^{20}$.

Nos anos 2011, 2012, e 2017 ocorreu um número expressivo de cancelamentos por troca de titularidade, podendo estar correlacionado com a Resolução n. 55/2010 ${ }^{24}$, que dispõe sobre o registro de produtos biológicos, e as Resoluções $\mathrm{n}$. $22 / 2010^{25}$ e n. $102 / 2016^{26}$, que facilitaram a troca de titularidade. Em 2010, além da nova regulamentação da comercialização dos produtos biológicos, por meio da RDC n. 55/201024, também ocorreu a simplificação do processo de transferência, minimizando a burocracia ${ }^{25}$, e em 2016 ampliou-se a transferência de titularidade não apenas para operações societárias, mas também para as operações comerciais, permitindo casos que envolviam simplesmente compra e venda de ativos $^{26}$.

O número expressivo de cancelamentos de registros em 2016 foi referente às vacinas de influenza, demonstrando a rotatividade do mercado. Em 2009 e 2010, com a pandemia de influenza, várias empresas registraram seu produto no mercado, porém com o passar dos anos, a autossuficiência da produção da vacina pelo Instituto Butantan para fornecer o produto ao PNI, reduziu o mercado de venda das empresas privadas, $\mathrm{e}$ muitas não renovaram o registro. Os contextos sanitários, regulatórios e econômicos propiciam a inclusão de produtos no mercado (pandemia, epidemia, ampliação/incorporação no PNI), assim como a retirada de produtos no mercado (autossuficiência de laboratórios públicos, pós pandemia/epidemia).

No âmbito da produção de vacinas em laboratórios privados, o aumento do registro de vacinas na Anvisa, a partir de 1993, não significa uma disseminação de produtores, sendo que quatro empresas possuem $63,0 \%$ da detenção dos processos de registro sanitário. No Brasil, assim como no mercado internacional ${ }^{27}$, observa-se um 
oligopólio, com predomínio de poucas empresas no mercado, realizando fusão ou transferência de empresas para desenvolvimento de tecnologias, principalmente dos produtos biotecnológi$\cos ^{20,28-30}$, coerente com o número expressivo de cancelamento de processos diante da troca de titularidade observada neste estudo.

Entre as vacinas disponibilizadas no calendário vacinal, a partir de 2004, como tentativa de garantir acesso às tecnologias, todas apresentavam registro sanitário ativo antes da disponibilização no sistema de saúde. O registro sanitário no país previamente à incorporação potencializa a possibilidade de acesso, ao garantir segurança, eficácia e qualidade do produto, além de favorecer a negociação de preço e a formalização de contratos comerciais.

Mesmo com essa estratégia de manter as vacinas com registro ativo no país, após o cancelamento da vacina pentavalente houve desabastecimento e o país tornou-se dependente de importação ${ }^{31}$. Em 2017, iniciou o processo de incorporação da tecnologia pelo Instituto Butantan, porém o processo ainda não foi finalizado ${ }^{32}$ Outra imunização, disponibilizada pelo PNI, em caso de surtos, porém sem registro ativo na Anvisa, é a dupla viral, que se encontra no processo de transferência de tecnologia com Bio -Manguinhos, mas sem informações adicionais ${ }^{33,34}$.

O número de cancelamentos de registros sanitários por empresas privadas é superior ao setor público, uma vez que as empresas públicas têm o objetivo de produzir vacinas essenciais para o país, considerando o PNI. Isso faz com que os laboratórios públicos mantenham os registros sanitários ativos, possibilitando garantir acesso à tecnologia, sempre que necessário, de forma a permitir o combate às doenças imunopreveníveis. O setor privado realiza a inovação incremental, patenteia, registra e insere no mercado, sendo fornecedor complementar ao PNI, este o grande comprador de vacinas no país. Os setores públicos, principalmente por meio das parcerias de transferências de tecnologias, assumem uma representatividade, ou mesmo autossuficiência para fornecimento dessas vacinas ao PNI, resultando no cancelamento de alguns registros sanitários dos produtos sob domínio do setor privado. Este como estratégia, por diversas vezes, realiza o lançamento de "novas" tecnologias, para ganhar novamente o mercado.

Ao analisar as vacinas do setor privado e não incorporadas no PNI, até 2018 (Tabela 2), observa-se que, $50 \%$ destas são produtos que conferem imunização semelhante às disponibilizadas no setor público, porém em associação. A associação de vacinas representa uma comodidade ao paciente, entretanto também pode ocasionar um risco adicional em termos de segurança, como reações alérgicas, além de, na maioria das vezes, possuir um custo adicional, pois requer desenvolvimento tecnológico e, consequentemente, investimento em pesquisa. Em contrapartida, as vacinas disponibilizadas no setor privado e incorporadas no PNI podem ser denominadas como complementares, possibilitando a ampliação da cobertura, a qual pode ser restrita a alguns grupos, conforme apresentado na Figura 2. Por exemplo, a vacina influenza, no calendário vacinal, é direcionada a grupos de maior risco, e nas clínicas de vacinação privadas, outras populações podem ter acesso.

Por outro lado, a produção de vacinas do PNI pelo setor privado pode ser complementar ao suprimento da demanda de imunização da população no setor público, especialmente em campanhas de maior amplitude.

De maneira geral, os dados desse trabalho possibilitam observar que o registro sanitário de vacinas no Brasil tem sido muito dinâmico, com presença tanto de empresas privadas, quanto públicas, e concentração dos registros em poucas empresas. Considerando os dados apresentados pela Abiquifi (Associação Brasileira da Indústria de Insumos Farmacêuticos), que apontam que o Brasil produz apenas 5\% dos insumos farmacêuticos ativos (IFA) de que necessita ${ }^{35}$, a produção nacional de vacinas é essencialmente de transformação.

A necessidade de estímulo do desenvolvimento do complexo econômico industrial nesse segmento é corroborada pelos achados de Gadelha e colaboradores ${ }^{20}$, os quais indicam que a produção nacional de vacinas é feita por laboratórios públicos e, muitas vezes, a partir de processos de transferência de tecnologias. Embora esta estratégia de internalização de tecnologias seja importante no cenário nacional, a superação das assimetrias em relação ao contexto global nesse campo exige a adoção de políticas públicas voltadas ao desenvolvimento do Complexo Econômico Industrial da Saúde (CEIS), com o estímulo às ações de pesquisa, desenvolvimento e inovação no campo das vacinas. Aspecto ainda mais evidenciado com a pandemia vivenciada em 2020.

Desde 2020, vivencia-se uma situação semelhante à experimentada com a influenza em 2009. Diante da pandemia do COVID-19, parcerias promissoras entre a Universidade de Oxford/ AstraZeneca e Fiocruz e a empresa Sinovac Life 
Science e o Instituto Butantan desenvolveram em tempo recorde, pela experiência já adquirida de outros imunizantes ${ }^{36}$, a produção da vacina contra o coronavírus para a população. Todos os insumos e imunizantes são provenientes da China ou Índia, ficando o país dependente de questões diplomáticas, que no momento estão desestabilizadas. Infelizmente, o negacionismo e as tomadas de decisão equivocadas do governo brasileiro diante da pandemia do COVID-19 macularam a expertise brasileira construída em programas de imunização em massa.

Por fim, cumpre informar que por se tratar de um estudo exploratório outros detalhes como tipo de tecnologias a serem disponibilizadas no PNI (vírus atenuado, inativo ou subunidades), assim como a cobertura populacional (idade especifica de utilização de cada tecnologia e esquema vacinal) representam lacunas neste estudo, e podem ser apresentadas em estudos posteriores.

\section{Conclusões}

A Anvisa certifica a eficácia, segurança e qualidade dos produtos no mercado, por meio da regulamentação sanitária do comércio. Entretanto, esse trabalho demonstrou a existência de lacunas na base de dados que disponibiliza as informações sobre os registros de vacinas (no momento da coleta de dados - 31/12/2018), tanto em relação à limitação temporal (dados disponíveis somente a partir de 1993), quanto à falta de informações, como por exemplo, sobre as empresas envolvidas na transferência de titularidade. Considerando que a base apresenta informações sobre medicamentos biológicos registrados desde a década de 1970, parece viável e considera-se de extrema importância o aprimoramento do sistema de disponibilização de informações sobre o registro de todos os produtos, como as vacinas, comercializados no país, de forma a construir a identidade histórica do setor.
O Brasil apresenta uma importante política de imunização, para a qual desenvolveu estratégias como o PNI, calendários vacinais, possibilitou a produção das vacinas essenciais para a população, e está possibilitando a sustentabilidade do setor, conferindo ao país o status de referência no controle das doenças imunopreveníveis, até a pandemia.

No entanto, mesmo com o sucesso do programa de imunização no decorrer dos anos, a produção nacional ainda está centrada na transferência de tecnologias ou importação de insumos ativos necessitando investimentos e atenção pública para desenvolver novas tecnologias e garantir a independência do setor. $\mathrm{O}$ mercado das imunizações, principalmente no que se refere ao desenvolvimento tecnológico, ao processo de incorporação e ao acesso da população, é um campo de pesquisa nuclear para o fortalecimento da política do país neste setor. As notícias recentes sobre a pesquisa e desenvolvimento da vacina para combater a COVID-19 e a discussão em torno de sua incorporação, embora não tenham constituído objeto deste estudo, parecem evidenciar a mesma conclusão. Os dados identificados no estudo, especialmente àqueles que mostram o predomínio de registros por empresas privadas, indicam a necessidade de investimentos para que a estratégia nacional de internalização de tecnologia por meio de parcerias ou contratos de transferência de tecnologia seja acompanhada por iniciativas de pesquisa, desenvolvimento e inovação no campo das vacinas, sob pena de manutenção da dependência nacional nesse segmento.

Os resultados mostram que o Brasil tem potencial industrial para a produção de vacinas, que poderia ser mobilizado por meio de políticas públicas bem coordenadas para contribuir para o atendimento tanto das necessidades do país como mundiais. Nesse contexto, destacam-se as estruturas produtivas públicas com experiência acumulada nesse campo, com destaque para o Instituto de Tecnologia em Imunobiológicos (Bio -Manguinhos/Fiocruz) e o Instituto Butantan. 


\section{Colaboradores}

KC Peres, NR Bonetti, L Soares, CM Vargas-Peláez e MR Farias participaram da concepção, planejamento, discussão e revisão final do artigo. EA Prates, FB Buendgens e KC Peres contribuíram para análise dos resultados, discussão e revisão da redação do manuscrito.

\section{Referências}

1. Brasil. Decreto no 78.231, de 12 de agosto de 1976. Regulamenta a Lei no 6.259 , de 30 de outubro de 1975 , que dispõe sobre a organização das ações de Vigilância Epidemiológica, sobre o Programa Nacional de Imunizações, estabelece normas relativas à notificação compulsória de doenças, e dá outras providências. Diário Oficial da União 1976; 12 ago.

2. Manguinhos vol III. A Produção e o Desenvolvimento de Vacinas no Brasil. Debate. Março-junho, 1996 [acessado 2021 abr 20]. Disponível em: https://www. scielo.br/pdf/hcsm/v3n1/v3n1a08.pdf.

3. Gadelha C, Azevedo N. Inovação em vacinas no Brasil: experiência recente e constrangimentos estruturais. Hist Cienc Saude Manguinhos 2003; 10(2):697-724.

4. Benchimol JL, coordenador. O Programa Nacional de Imunizações. In: Febre amarela: a doença e a vacina, uma história inacabada [online]. Editora Fiocruz 2001; p.320-322. [acessado 2021 mar 15]. Disponível em: https://static.scielo.org/scielobooks/4nktq/pdf/benchimol-9788575413951.pdf.

5. Brasil. Ministério da Saúde (MS). Sistema de Informação do Programa Nacional de Imunizações - Apresentação [online] [acessado $2020 \mathrm{dez} 29$ ]. Disponível em: http://pni.datasus.gov.br/apresentacao.asp.

6. Brasil. Ministério da Saúde (MS). Programa Nacional de Imunizações - 30 anos. [online] [acessado $2020 \mathrm{dez}$ 29]. Disponível em: https://bvsms.saude.gov.br/bvs/ publicacoes/livro_30_anos_pni.pdf.

7. Brasil. Ministério da Saúde. Brasil é referência mundial em produção de vacinas. [online] [acessado 2020 dez 29]. Disponível em: http://www.blog.saude.gov. br/index.php/52930-brasil-e-referencia-mundial-em -producao-de-vacinas.

8. Gava CM, Bermudez JAZ, Pepe VLE, Reis ALAD. Novos medicamentos registrados no Brasil: podem ser considerados como avanço terapêutico? Cien Saude Colet 2010; 15(3):3403-3412.

9. Aith FMA, Cunha ACNMF, Castellaro FAB, Soares DFL, Dallari SG. Regulação de medicamentos no Brasil: desafios no contexto do mundo globalizado. In: Regulação de medicamentos no mundo globalizado. São Paulo, Centro de Estudos e Pesquisas de Direito Sanitário 2014:31-46.

\section{Financiamento}

Este artigo contou com o financiamento de bolsa de doutorado pela Coordenação de Aperfeiçoamento de Pessoal de Nível Superior - Brasil (CAPES).

10. Aith FMA, Dallari SG. São Paulo; Centro de Estudos e Pesquisas de Direito Sanitário 2014: 636 p.

11. Costa EA, Fernandes TM, Pimenta TS. A vigilância sanitária nas políticas de saúde no Brasil e a construção da identidade de seus trabalhadores (1976-1999). Cien Saude Colet 2008; 13(3):995-1004.

12. Brasil. Lei n. 9.782, de 26 de janeiro de 1999. Define o Sistema Nacional de Vigilância Sanitária, cria a Agência Nacional de Vigilância Sanitária, e dá outras providências. Diário Oficial da União 1999; 26 jan.

13. Silva JAA, Costa EA, Lucchese, G. SUS 30 anos: Vigilância Sanitária. Cien Saude Colet 2018; 23(6):19531962.

14. Brasil. Agência Nacional de Vigilância Sanitária. Consulta Anvisa-Medicamentos e hemoderivados [online] [acessado $2020 \mathrm{dez} 29$ ]. Disponível em: https://consultas.anvisa.gov.br/\#/medicamentos/.

15. Brasil. Agência Nacional de Vigilância Sanitária. Consulta Anvisa. Situação de documentos - tipo de documento técnico [online] [acessado $2020 \mathrm{dez} 29$ ]. Disponível em: https://consultas.anvisa.gov.br/\#/documentos.

16. Brasil. Conselho Nacional da Saúde. Resolução n. 510, de 07 de abril de 2016. Dispõe sobre as normas aplicáveis a pesquisas em Ciências Humanas e Sociais cujos procedimentos metodológicos envolvam a utilização de dados diretamente obtidos como participantes ou de informações identificáveis ou que possam acarretar riscos maiores do que os existentes na vida cotidiana, na forma definida nesta Resolução. Publicado em: 2016, maio 24, 2016, 98(1), p. 44.

17. SAID DMP. Registro Sanitário de medicamentos: uma experiência de revisão [dissertação]. Rio de Janeiro: Instituto Nacional de Controle de Qualidade em Saúde, Fundação Oswaldo Cruz; 2004.

18. Brasil. Portaria no 1.498 , de 19 de julho de 2013 Brasil. Redefine o Calendário Nacional de Vacinação, o Calendário Nacional de Vacinação dos Povos Indígenas e as Campanhas Nacionais de Vacinação, no âmbito do Programa Nacional de Imunizações (PNI), em todo o território nacional. [acessado 2021 mar 14]. Disponível em: http://bvsms.saude.gov.br/bvs/saudelegis/ gm/2013/prt1498_19_07_2013.html. 
19. Chaves CG, Moraes EL, Osorio-de-Castro CGS. Estratégias de produção e aquisição de produtos farmacêuticos em contexto de dependência. Cad Saude Publica 2021; 37(3):e00036821.

20. Gadelha CAG, Braga PSC, Montenegro KBM, Cesário BB. Acesso a vacinas no Brasil no contexto da dinâmica global do Complexo Econômico-Industrial da Saúde. Cad Saude Publica 2020; 36(2):e00154519.

21. São Paulo. Secretaria de Estado da Saúde de São Paulo. Instituto Butantan - A serviço da vida. São Paulo: SES; 2019. [acessado 2021 mar 01]. Disponível em: https:// butantan.gov.br/noticias/butantan-comemora-20-anos-de-parceria-com-farmaceutica-francesa-paracombate-a-gripe-no-brasil.

22. São Paulo. Secretaria de Estado da Saúde de São Paulo. Instituto Butantan - A serviço da vida. São Paulo: SES 2020. [acessado 2021 mar 01]. Disponível em: https:// butantan.gov.br/noticias/em-feito-historico-butantan-vai-exportar-550-mil-doses-da-vacina-contra-agripe-.

23. Agência Brasil. Butantan vai exportar vacinas contra a gripe para países asiáticos. São Paulo: SES; 2020. [acessado 2021 mar 01]. Disponível em: https://agenciabrasil.ebc.com.br/saude/noticia/2020-08/butantan-vai-exportar-vacinas-contra-gripe-para-paises-asiaticos.

24. Brasil. Agência Nacional de Vigilância Sanitária (Anvisa). Resolução - RDC no 55, de 16 de dezembro de 2010. Dispõe sobre o registro de produtos biológicos novos e produtos biológicos e dá outras providências. [online] [acessado 2021 jun 28]. Disponível em: https://bvsms.saude.gov.br/bvs/saudelegis/anvisa/2010/ res0055_16_12_2010.html.

25. Brasil. Agência Nacional de Vigilância Sanitária. Resolução - RDC no 22, de 17 de junho de 2010. Dispõe sobre a regulamentação da transferência de titularidade de registro de produtos sujeitos à vigilância sanitária em razão de operações societárias. Brasília: Anvisa; 2010. [acessado 2021 abr 12]. Disponível em: http://www.sbpc.org.br/ upload/noticias_setor/320100625154151.pdf.

26. Brasil. Ministério da Saúde (MS). Agência Nacional de Vigilância Sanitária (Anvisa). Resolução - RDC no 102, de 24 de agosto de 2016. Dispõe sobre os procedimentos para a transferência de titularidade de registro de produtos sujeitos à vigilância sanitária, transferência global de responsabilidade sobre ensaio clínico e atualização de dados cadastrais relativos ao funcionamento e certificação de empresas, em decorrência de operações societárias ou operações comerciais. Diário Oficial da União, 2016; ago 25.

27. Evaluate Pharma. World Preview 2018, outlook to 2024. [online] [acessado em $2020 \mathrm{dez}$ 29]. Disponível em: http://info.evaluategroup.com/rs/607-YGS-364/images/WP2018.pdf.

28. Homma A, Martins RM, Leal MLF, Freire MS, Couto AR. Atualização em vacinas, imunizações e inovação tecnológica. Cien Saude Colet 2011; 16(2):445-458.

29. Gadelha CAG, Nascimento MAC, Braga PSC, Cesário BB. Transformações e assimetrias tecnológicas globais: estratégia de desenvolvimento e desafios estruturais para o Sistema Único de Saúde. Cien Saude Colet 2018; 23:2119-2132.
30. Bahia L, Scheffer M, Tavares LR, Braga IF. From health plan companies to international insurance companies: changes in the accumulation regime and repercussions on the healthcare system in Brazil. Cad Saude Publica 2016; 32 (2):e00154015.

31. Souza L. Em falta, vacina pentavalente começa a ser distribuída aos estados. Veja Saúde [acessado 2020 dez 29]. Disponível em: https://saude.abril.com.br/medicina/vacina-pentavalente-distribuida-aos-estados.

32. Brasil. Ministério da Saúde (MS). Vacina Pentavalente passa a ser produzida e adquirida no Brasil. Blog da Saúde. Brasília: MS; 2017. [acessado em 2020 dez 29]. Disponível em: http://www.blog.saude.gov.br/index. php/entenda-o-sus/52359-vacina-pentavalente-passa -a-ser-produzida-e-adquirida-no-brasil.

33. Labnetwork. $100 \%$ nacional: vacinas contra sarampo e rubéola do Brasil para o mundo. $B D$. [online] [acessado em 2020 dez 29. Disponível em: https://www. labnetwork.com.br/noticias/100-nacional-vacinascontra-sarampo-e-rubeola-do-brasil-para-o-mundo/. Publicado em 2013; oct 31.

34. Fundação Oswaldo Cruz (Fiocruz). Brasil vai exportar vacina contra sarampo e rubéola a partir de 2017. [online] [acessado em 2020 dez 29]. Disponível em: https:// portal.fiocruz.br/noticia/brasil-vai-exportar-vacinacontra-sarampo=-e-rubeola-partir-de2017-\#: :textBiomanguinhos\%2FFiocruz,-O\%20laborat \%$\mathrm{C} 3 \% \mathrm{~B} 3$ rio\%20Biomanguinhos\&text $=\mathrm{O} \% 20 \mathrm{Brasil} \%$ 20produz\%20atualmente $\% 2096$,para $\% 2075 \% 20$ pa\%C3\%ADses\% 20no\%20mundo. Publicada 2013; oct 29 .

35. Santos S. Em quatro décadas, Brasil reduz de 55\% para $5 \%$ capacidade de produção de insumos farmacêuticos. Folha de São Paulo 2021; 20 fev. [online] [acessado em 27/04/2021]. Disponível em: https:// wwwl.folha.uol.com.br/autores/sheyla-santos.shtml.

36. Instituto de Ciência, Tecnologia e Qualidade (ICTQ). Por que a vacina contra covid-19 foi desenvolvida em tempo recorde. [online] [acessado $2021 \mathrm{mar}$ 01]. Disponível em: https://www.ictq.com.br/farmaciaclinica/2636-por-que-a-vacina-contra-covid-19-foi-desenvolvida-em-tempo-recorde.

Artigo apresentado em 29/12/2020

Aprovado em 07/07/2021

Versão final apresentada em 09/07/2021

Editores-chefes: Romeu Gomes, Antônio Augusto Moura da Silva 